\title{
Pharmacokinetics, hemodynamic and metabolic effects of epinephrine to prevent post-operative low cardiac output syndrome in children
}

\author{
Mehdi Oualha ${ }^{1,2^{*}}$, Saïk Urien², Odile Spreux-Varoquaux ${ }^{3}$, Alice Bordessoule ${ }^{4}$, Irène D'Agostino ${ }^{4}$,
} Philippe Pouard ${ }^{4}$ and Jean-Marc Tréluyer ${ }^{2}$

\begin{abstract}
Introduction: The response to exogenous epinephrine (Ep) is difficult to predict given the multitude of factors involved such as broad pharmacokinetic and pharmacodynamic between-subject variabilities, which may be more pronounced in children. We investigated the pharmacokinetics and pharmacodynamics of Ep, co-administered with milrinone, in children who underwent open heart surgical repair for congenital defects following cardiopulmonary bypass, including associated variability factors.

Methods: Thirty-nine children with a high risk of low cardiac output syndrome were prospectively enrolled. Ep pharmacokinetics, hemodynamic and metabolic effects were analyzed using the non-linear mixed effects modeling software MONOLIX. According to the final model, an Ep dosing simulation was suggested.

Results: Ep dosing infusions ranged from 0.01 to $0.23 \mu \mathrm{g} \cdot \mathrm{kg}^{-1} \cdot \mathrm{min}^{-1}$ in children whose weight ranged from 2.5 to $58 \mathrm{~kg}$. A one-compartment open model with linear elimination adequately described the Ep concentration-time courses. Bodyweight $(B W)$ was the main covariate influencing clearance $(\mathrm{CL})$ and endogenous Ep production rate (q0) via an allometric relationship: $\mathrm{CL}(\mathrm{BWi})=\theta_{\mathrm{CL}} \times(\mathrm{BWi})^{3 / 4}$ and $\mathrm{qO}(\mathrm{BWi})=\theta_{\mathrm{q} 0} \times(\mathrm{BWi})^{3 / 4}$. The increase in heart rate (HR) and mean arterial pressure (MAP) as a function of Ep concentration were well described using an Emax model. The effect of age was significant on HR and MAP basal level parameters. Assuming that Ep stimulated the production rate of plasma glucose, the increases in plasma glucose and lactate levels were well described by turnover models without any significant effect of age, BW or exogenous glucose supply.

Conclusions: According to this population analysis, the developmental effects of BW and age explained a part of the pharmacokinetic and pharmacodynamics between-subject variabilities of Ep administration in critically ill children. This approach ultimately leads to a valuable Ep dosing simulation which should help clinicians to determine an appropriate a priori dosing regimen.
\end{abstract}

\section{Introduction}

Inotropic agents are commonly administered to prevent postoperative low cardiac output syndrome (LCOS) following cardiopulmonary bypass (CPB) in children undergoing open heart surgical repair [1]. According to the PRIMACORP study, milrinone is the first-choice drug [2].

\footnotetext{
* Correspondence: mehdi.oualha@nck.aphp.fr

${ }^{1}$ Réanimation Pédiatrique. Hôpital Necker Enfants-Malades, Assistance Publique-Hôpitaux de Paris, Université Paris Descartes, Paris, France

${ }^{2} \mathrm{CIC}-0109$ Cochin-Necker Inserm, Unité de Recherche Clinique, Paris Centre Descartes Necker Cochin, Service de Pharmacologie Hôpital Cochin, Assistance Publique- Hôpitaux de Paris et E.A. 3620, Université Paris Descartes, Paris, France Full list of author information is available at the end of the article
}

However as described in the European survey EuLoCOSPaed, preventive drug therapy is highly variable. For instance, epinephrine (Ep), which is cheaper than other commonly used catecholamines, is also used, although evidenced-based data are currently lacking [3,4].

The amplitude of the hemodynamic response to Ep is difficult to predict given the multitude of factors involved and clinical experience suggests broad between-subject variability. This hemodynamic response is primarily dependent on Ep concentrations. However Ep pharmacokinetics has been poorly evaluated in children. Fisher et al. suggested linear pharmacokinetics with a lower clearance than that reported in healthy adults, although

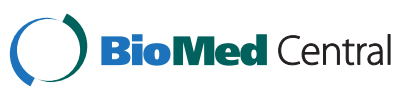


only six children were included in their study and neither inter-patient variability nor pharmacodynamic effects were described [5]. A recent adult study using population pharmacokinetic modeling highlighted the influence of bodyweight (BW) and disease severity on Ep clearance confirming this variability [6]. These between-subject disparities may be even more pronounced in children.

Pediatric dosages of Ep are usually extrapolated from adult studies. However, postnatal development of cardiac contractility is associated with major changes in the modulatory effect of $\beta$-adrenoreceptor signaling. Moreover, differential maturation of the transduction pathways within the cardiomyocyte contributes to age-dependent changes in cardiac responsiveness and sensitivity to agonists [7]. Although much is known regarding the adult physiological and pharmacological effects of Ep, there are very few pediatric studies on Ep pharmacodynamics. Effects of Ep infusion in children have only been described in the neonate, mostly in low birth-weight infants, where effects on heart rate (HR), mean arterial pressure (MAP), plasma glucose and lactate levels were observed [8].

The purpose of the present study was to investigate, using a population approach, the pharmacokinetics and pharmacodynamics of Ep including hemodynamic (HR, MAP) and metabolic effects (plasma glucose and lactate levels) in critically ill children undergoing surgical repair for congenital heart defect, following $\mathrm{CPB}$, as well as associated variability factors [9]. The effects of developmental and other factors on Ep pharmacokinetics and pharmacodynamics were investigated in order to better explain the observed between-subject variabilities and to ultimately suggest individualized dosage regimens.

\section{Materials and methods}

\section{Setting}

This prospective study was conducted in a 14-bed surgical pediatric cardiovascular intensive care unit (pCVICU) of a tertiary teaching hospital Necker Enfants Malades, Paris in France from July 2011 to December 2011. The Ethics committee of the Necker Enfants Malades Hospital approved the study provided that written and appropriate consent was obtained from the child's parent(s) after they were informed of the objectives. We confirm that we have all necessary and appropriate consent from each child's parents involved in the study, including consent to participate in the study and consent to publish.

All consecutive children aged less than 18 years, weighing more than 1,200 g, and requiring Ep infusion following CPB for open heart surgery were included. Non-inclusion criteria were unknown initial time infusion of Ep, unknown time of Ep flow-rate changes or unknown time of blood sampling. Children were enrolled prior to the onset of infusion and for a period lasting 6 hours after the start of Ep administration.

\section{Intervention}

In the operating room, all children underwent endotracheal intubation and were mechanically ventilated under sedation, opioid treatment (midazolam and sufentanil) and neuromuscular blocking agent. Standard monitoring was used, comprising a radial or femoral artery catheter for measurement of systemic arterial blood pressure and intermittent blood sampling, a triple-lumen right internal jugular or femoral central venous catheter (CVC), and urinary bladder or rectal temperature probes. Normothermic CPB with intermittent warm blood cardioplegia was performed in every patient during the study period, except in cases where deep hypothermic circulatory arrest was indicated. Conventional ultrafiltration was performed during the $\mathrm{CPB}$.

Ep infusion was initiated in the operating room (defined as time $=0$ minutes), in association with milrinone at the end of the $\mathrm{CPB}$, according to the local protocol and the risk of developing an LCOS: risk adjustment for congenital heart surgery 1 (RACHS-1) category, aortic crossclamping duration, preoperative left ventricle dilatation, preoperative or intraoperative arterial pulmonary hypertension defined by intra cardiac right to left shunt or pulmonary arterial pressure over $2 / 3$ mean systemic arterial pressure, hemodynamic instabilities (defined by a variation greater than $20 \%$ of HR and/or MAP) and physiological status $[2,10]$. Cases involving sepsis or preoperative myocardial dysfunction requiring inotropic support were excluded.

Ep (adrenalin $1 \mathrm{mg} \cdot \mathrm{mL}^{-1}$, Renaudin ${ }^{\mathrm{TM}}$ diluted to $100 \mu \mathrm{g} \cdot \mathrm{mL}^{-1}$ or $50 \mu \mathrm{g} \cdot \mathrm{mL}^{-1}$ in Glucose $5 \%$ Baxter $^{\mathrm{TM}}$, UK) was infused using a programmable electric syringe pump (DPS, Fresenius Vial ${ }^{\mathrm{TM}}$, Brezins, France) through a triplelumen central venous catheter (Arrow, Teleflex ${ }^{\mathrm{TM}}$, PA 19605 , USA) with a flow rate varying from $0.3 \mathrm{~mL} \cdot \mathrm{h}^{-1}$ to $1 \mathrm{~mL} \cdot \mathrm{h}^{-1}$. The latter was adjusted for age and hemodynamic objectives, namely: normal HR, normal MAP, normal time capillary refill, normal pulse, normal urine output $\left(>2 \mathrm{~mL} \cdot \mathrm{kg}^{-1} \cdot \mathrm{h}^{-1}\right), \mathrm{ScVO} 2>70 \%$ when measured, normal transthoracic echocardiography of left ventricular ejection fraction (60 to $80 \%)$ and normal plasma lactate level $\left(<2.2 \mathrm{mmol} \cdot \mathrm{L}^{-1}\right)[2,11]$. Depending on the congenital heart defects and the repair, the preload was normalized based on CVP and/or left atrial pressure (LAP). After normalized preload, intravenous milrinone at a dose ranging from 0.3 to $0.5 \mu \mathrm{g} \cdot \mathrm{kg}^{-1} \cdot \mathrm{min}^{-1}$ was systematically combined with Ep infusion without loading bolus at initiation.

Upon arrival to the ICU, medications were adjusted by the bedside nurse under the direction of the medical team: blood transfusion to reach a hemoglobin level above $10 \mathrm{~g} \cdot \mathrm{dL}^{-1}$, furosemide to maintain water balance and urine output over $2 \mathrm{~mL} \cdot \mathrm{kg}^{-1} \cdot \mathrm{h}^{-1}$. Adequate analgesia and sedation were ensured by, respectively, continuous 
intravenous morphine or sufentanil and midazolam, mechanical ventilation with adequate pressure levels and oxygen inspired fraction and inhaled nitric oxide in case of pulmonary arterial hypertension.

The daily amount of intravenous glucose was adjusted for age: birth to 12 months: $4 \mathrm{~g} \cdot \mathrm{kg}^{-1} \cdot \mathrm{day}^{-1}, 12$ months to 48 months: $3 \mathrm{~g} \cdot \mathrm{kg}^{-1} \cdot \mathrm{day}^{-1}$, 48 months to 72 months: $2.5 \mathrm{~g} \cdot \mathrm{kg}^{-1} \cdot \mathrm{day}^{-1}$ and over 72 months: $2 \mathrm{~g} \cdot \mathrm{kg}^{-1} \cdot \mathrm{day}^{-1}$.

LCOS was defined if Ep and/or milrinone were needed over 48 hours to maintain normal hemodynamic parameters (normal HR, normal urine output, normal MAP, normal capillary refill time, warm extremities) without metabolic acidosis (standard plasma bicarbonate $\left(\mathrm{HCO}_{3}^{-}\right)$ level less than $22 \mathrm{mmol} \cdot \mathrm{L}^{-1}$ or an increase in plasma lactate level greater than $2.2 \mathrm{mmol} \cdot \mathrm{L}^{-1}$ ) $[2,11]$. In this study, no other catecholamines or corticosteroid was used in the first 6 hours following open heart surgery.

\section{Blood sampling}

An initial blood sample $\left(\mathrm{C}_{0}\right)$ was collected prior to $\mathrm{CPB}$ after which $\mathrm{Ep}$ infusion was initiated. A second blood sample $\left(C_{1}\right)$ was drawn at least 60 minutes after initiating Ep infusion. A last blood sample $\left(\mathrm{C}_{2}\right)$ was drawn 40 minutes after a change in rate flow or prior to 6 hours after beginning Ep infusion in the case of a constant flow rate.

The 60-minute steady-state interval was chosen according to at least five times the Ep plasma half-life in healthy subjects (approximately 20 minutes) and the dead volume of the CVC used to infuse Ep at 0.3 to $1 \mathrm{~mL} \cdot \mathrm{h}^{-1}$ rate flow (approximately 40 minutes) [4].

$\mathrm{C}_{0}$ was used to assess plasma levels of endogenous Ep. Only $C_{0}$ and $C_{1}$ were drawn in patients who weighed less than 2,500 g, according to the percentage of blood volume permitted by the Ethics Committee of our institution.

\section{Sample handling}

Blood assigned to catecholamine assays was sampled in EDTA-tubes placed in an ice bucket then immediately centrifuged at 3,000 g for 5 minutes. The plasma samples were then separated and immediately stored at $-20^{\circ} \mathrm{C}$ and thereafter at $-80^{\circ} \mathrm{C}$ before 24 hours running.

\section{Assay}

Ep concentrations were blindly determined by means of HPLC with colorimetric detection [12]. After thawing, the volume of each sample was adjusted to $4 \mathrm{~mL}$ by adding distilled water and the internal standard, dihydroxybenzylamine. A $20-\mu \mathrm{L}$ aliquot at $10^{\circ} \mathrm{C}$ was then injected into the chromatographic system comprised of a column $(25 \mathrm{~cm} \times 4.6 \mathrm{~mm}$ inner diameter, $5 \mu \mathrm{m}$ Supelcosil LC-18 Supelco ${ }^{\mathrm{TM}}$ ), an electrochemical ESA colorimetric detector (Model Coulochem III, Eurosep ${ }^{\text {TM}}$ ), dual analytic cells (ESA cell Model 5011) set at $-0.05 \mathrm{~V}$ for the first detector and $-0.3 \mathrm{~V}$ for the second detector, and a conditioning cell set at $+0.3 \mathrm{~V}$. The mobile phase, at $1.2 \mathrm{~mL} \cdot \mathrm{min}^{-1}$, consisted of a mixture of an aqueous acidic buffer containing heptane sulfonic acid and acetonitrile $(93: 7 \mathrm{v} / \mathrm{v})$. Ep calibration curves were prepared according to the same procedure $(2.5 \mu \mathrm{g}$ to $75 \mu \mathrm{g} / 4 \mathrm{~mL}$ distilled water). The measured Ep concentration in $\mathrm{pmol} \cdot \mathrm{mL}^{-1}$ was converted to $\mu \mathrm{g} \cdot \mathrm{L}^{-1}$. The detection threshold (defined by variability $<10 \%$ between measurements) for HPLC was $0.2 \mathrm{pmol} \cdot \mathrm{mL}^{-1}$. Endogenous and exogenous Ep were strictly identical with regard to chromatographic detection.

\section{Patient data}

Baseline patient characteristics were recorded, including non-cardiac medical history, gender, age, BW, RACHS-1 category, type of congenital heart defect, preoperative cyanotic status and left ventricular ejection fraction, duration of CBP and aortic cross-clamping, duration of pCVICU stay, mechanical endotracheal ventilation duration and death during pCVICU stay. Duration of both Ep and milrinone infusion were recorded. Variation of infused doses was recorded during the first 6 hours.

HR (beats $\mathrm{min}^{-1}$ ) and invasive MAP $(\mathrm{mmHg}$ ) data were recorded prior to $\mathrm{CPB}$, at initiation of $\mathrm{Ep}$, and then every 10 minutes for the first hour and thereafter every hour or less if needed during the subsequent 6 hours. Left ventricular ejection fraction (\%) was measured at least once during the 6 hours. CVP ( $\mathrm{mmHg}$ ) was systematically recorded as well as LAP ( $\mathrm{mmHg}$ ) when measured. Temperature $\left({ }^{\circ} \mathrm{C}\right)$ and urine outputs $\left(\mathrm{mL} \cdot \mathrm{kg}^{-1} \cdot \mathrm{h}^{-1}\right)$ were recorded during 6 hours following CBP.

Plasma lactate and glucose levels $\left(\mathrm{mmol} \cdot \mathrm{L}^{-1}\right)$ were recorded before surgery and at least once thereafter during the following 6 hours. Arterial $\mathrm{pH}$, ionized plasma calcium levels $\left(\mathrm{mmol} \cdot \mathrm{L}^{-1}\right)$ and plasma $\mathrm{HCO}_{3}^{-}$levels $\left(\mathrm{mmol} \cdot \mathrm{L}^{-1}\right)$ were recorded during the first 6 hours.

Results are expressed as raw numbers (\%) or medians (ranges). The non-parametric Wilcoxon test was performed to compare pharmacokinetic and pharmacodynamic values before and under Ep infusion. $P<0.05$ was considered statistically significant.

\section{Pharmacokinetic-pharmacodynamic modeling}

Ep concentration time-courses were described by a onecompartment open model with first-order elimination with the parameters of elimination clearance $(\mathrm{CL})$ and volume of distribution (V). The differential equation connected to this model is thus,

$$
\begin{aligned}
\mathrm{dA}(\mathrm{t}) / \mathrm{dt} & =\text { Rate }-\mathrm{CL} \cdot \mathrm{C}(\mathrm{t}) \\
\text { with } \mathrm{C}(\mathrm{t}) & =\mathrm{A}(\mathrm{t}) / \mathrm{V}
\end{aligned}
$$

where $A(t)$ and $C(t)$ denote the amount of drug and concentration of drug in the body at time $t$. The endogenous 
production rate, $\mathrm{q} 0$, was taken into account in the model as follows,

$$
\mathrm{C}(\mathrm{t})=\mathrm{A}(\mathrm{t}) / \mathrm{V}+\mathrm{q} 0 / \mathrm{CL}
$$

The effect of BW was investigated in the pharmacokinetic model via an allometric relationship [13].

$$
\mathrm{P}=\mathrm{P}_{\mathrm{TYP}}(\mathrm{BW})^{\mathrm{PWR}}
$$

where $\mathrm{P}, \mathrm{P}_{\mathrm{TYP}}$ and PWR are the individual parameter, typical parameter and power exponent, respectively. The PWR exponent was estimated in a first attempt and then eventually fixed to $3 / 4$ for $\mathrm{CL}$ and q0 terms according to the typical weight-based allometric rule.

The circulating volume, $\mathrm{V}_{\text {Circ }}(\mathrm{L})$, was related to $\mathrm{BW}$ as follows [14].

$$
\mathrm{V}_{\text {Circ }}=0.08 . \mathrm{BW}
$$

As kinetics data were best described by a one-compartment model with first-order elimination, the half-life $\left(T_{1 / 2}\right)$ was related to $\mathrm{V}$ and $\mathrm{CL}$ as $\mathrm{T}_{1 / 2}=\ln 2 . \mathrm{V} / \mathrm{CL}=0.69 . \mathrm{V} / \mathrm{CL}$.

The HR response, HR(t), was related to the Ep concentration via an Emax model.

$$
\mathrm{HR}(\mathrm{t})=\mathrm{HR}_{0}+\left(\mathrm{HR}_{\max }-\mathrm{HR}_{0}\right) \cdot \mathrm{C}(\mathrm{t}) /\left\{\mathrm{C}(\mathrm{t})+\mathrm{C}_{50} \mathrm{HR}\right\}
$$

where $\mathrm{HR}_{\max }$ and $\mathrm{HR}_{0}$ are respectively the maximal and basal $\mathrm{HR}$ values and $\mathrm{C}_{50} \mathrm{HR}$ the concentration that induces $50 \%$ of the maximal effect on HR.

The MAP $(t)$ is then expressed as:

$$
\operatorname{MAP}(\mathrm{t})=\mathrm{HR}(\mathrm{t}) \cdot \operatorname{SV} \cdot \operatorname{SVR}(\mathrm{t})+\mathrm{CVP}
$$

where SV, SVR and CVP represent stroke volume, systemic vascular resistance and central venous pressure, respectively [15]. As SV and SVR were not known, the SV. SVR product variation was estimated via the function.

$$
\begin{aligned}
\operatorname{SV} \cdot \operatorname{SVR}(\mathrm{t})= & \mathrm{SV} \cdot \mathrm{SVR}_{0}+\left(\mathrm{SV} \cdot \mathrm{SVR}_{\max }-\mathrm{SV} \cdot \mathrm{SVR}_{0}\right) \cdot \mathrm{C}(\mathrm{t}) / \\
& \left\{\mathrm{C}(\mathrm{t})+\mathrm{C}_{50} \mathrm{SV} \cdot \mathrm{SVR}\right\}
\end{aligned}
$$

where SV.SVR 0 , SV.SVR $\max$ and $\mathrm{C}_{50} \mathrm{SV} \cdot \mathrm{SVR}$ respectively denote the SV.SVR product basal value, the product's maximal value and the concentration that induces 50\% of the maximal effect on SV.SVR.

Plasma glucose and lactate, $G(t)$ and $L(t)$, variations were modeled by a turnover model in which the stimulation of plasma glucose production, $\mathrm{S}(\mathrm{t})$, was related to Ep concentration as follows.

$$
\mathrm{dG}(\mathrm{t}) / \mathrm{dt}=\mathrm{R}_{\mathrm{GLY}} \cdot \mathrm{S}(\mathrm{t})-\mathrm{k}_{\mathrm{GLY}} \cdot \mathrm{G}(\mathrm{t})
$$

with

$$
\mathrm{S}(\mathrm{t})=1+\mathrm{G}_{\max } \mathrm{C}(\mathrm{t}) /\left\{\mathrm{C}(\mathrm{t})+\mathrm{C}_{50} \mathrm{GLY}\right\}
$$

where $\mathrm{R}_{\mathrm{GLY}}$ and $\mathrm{k}_{\mathrm{GLY}}$ represent the plasma glucose zeroorder rate production and first-order elimination rate constant. $G_{\max }$ and $\mathrm{C}_{50} \mathrm{GLY}$ denote respectively the maximal stimulation effect and the Ep concentration that produces $50 \%$ of the maximal response.

The rate of change in plasma lactate level, $\mathrm{dL}(\mathrm{t}) / \mathrm{dt}$, was related to the plasma glucose level variation rate as:

$$
\mathrm{dL}(\mathrm{t}) / \mathrm{dt}=\mathrm{k}_{\mathrm{GLY}} \cdot \mathrm{G}(\mathrm{t})-\mathrm{k}_{\mathrm{LAC}} \cdot \mathrm{L}(\mathrm{t})
$$

where $\mathrm{k}_{\mathrm{LAC}}$ is the plasma lactate elimination rate constant.

Before Ep infusion, the systems are assumed to be at steady-state,

$$
\begin{aligned}
\mathrm{G}(0)= & \mathrm{GLY}_{0}, \mathrm{~L}(0)=\mathrm{LAC}_{0} \text {, then } \mathrm{k}_{\mathrm{GLY}} \text { and } \mathrm{k}_{\mathrm{LAC}} \text { are } \\
\mathrm{k}_{\mathrm{GLY}} & =\mathrm{R}_{\mathrm{GLY}} / \mathrm{GLY}_{0} \\
\mathrm{k}_{\mathrm{LAC}} & =\mathrm{k}_{\mathrm{GLY}} \cdot \mathrm{GLY}_{0} / \mathrm{LAC}_{0}
\end{aligned}
$$

where $\mathrm{GLY}_{0}$ and $\mathrm{LAC}_{0}$ denote respectively, basal plasma glucose and lactate levels.

\section{Population pharmacokinetic-pharmacodynamic analysis}

Drug concentrations and responses were analyzed using a population approach, that is, a non-linear mixed-effect modeling approach. Data were analyzed using the MONOLIX software version $4.13 \mathrm{~s}$ [16] and the SAEM algorithm [17]. Differential equations were written in an MLXTRAN script file in MONOLIX to estimate the parameters. Residual variabilities were described by additive, proportional or exponential error models depending on the observation. An exponential model was used for between-subject variability (BSV). The effect of a covariate on a structural parameter was retained if it caused a decrease in the Bayesian information criterion (BIC) and/or reduced the corresponding BSV with $P<0.05$. Only covariates with a plausible effect on pharmacokinetic and pharmacodynamic parameters were investigated. The main covariates of interest in this pediatric population were BW and age.

\section{Visual predictive check (VPC) evaluation}

Plasma Ep concentration, HR, MAP, plasma glucose and lactate-level time course was simulated from the respective final population model and compared with the observed data to evaluate the predictive performance of the model. The vector of pharmacokinetic parameters from 400 replicates of the database was simulated using the final model. Each vector parameter was drawn in a log-normal distribution with a variance corresponding to the previously estimated BSV. A simulated residual error was added to each simulated concentration. The 5th, 50th and 95th percentiles of the simulated dependent variables at each time point were then overlaid on the observed data and a visual inspection was performed. Because the patients received different Ep regimens, the Uppsala correction was used to produce the VPC plots [18]. 


\section{Evaluation and validation}

Diagnostic graphics were used for evaluation of the goodness-of-fit. Concentration and effects profiles were simulated and compared with the observed data with the aid of the VPC in order to validate the model.

\section{Results \\ Patients}

A total of 55 children were initially enrolled, of which 16 patients were subsequently excluded: 6 because of incomplete parental consent, 7 because of missing $C_{1}$ and $C_{2}$ blood samples and 2 because of hemolysis.

Hence, 39 children were included in the study. $\mathrm{C}_{0}$ samples were obtained in 33 patients, $C_{1}$ in all children and $C_{2}$ in 25 children for a total of 97 observations. Hemodynamic data (HR, MAP) and metabolic effects of Ep infusion (plasma lactate and glucose levels) were available in 38 children with 434, 464, 101 and 140 observations, respectively.

Five premature children with a gestational age $<37$ weeks ( $\mathrm{n}=1$ at 33 weeks, $\mathrm{n}=1$ at 34 weeks, and $\mathrm{n}=3$ at 36 weeks) were recorded. Chromosomal disorders were reported in eight children ( $\mathrm{n}=3$ with Down syndrome, $\mathrm{n}=1$ with di George syndrome, $\mathrm{n}=1$ with Loeys-Dietz syndrome, and $n=1$ with Noonan syndrome $n=2$ with suspected Noonan syndrome). Respiratory disorders were noted in seven patients ( $\mathrm{n}=3$ with asthma, $\mathrm{n}=3$ with laryngotracheomalacia, and $\mathrm{n}=1$ with chronic aspiration pneumonia) and malnutrition $(<2 \mathrm{SD})$ was observed in nineteen children.

Six children were treated before open heart surgery with converting enzyme inhibitors because of left ventricular dilatation, seven were treated with prostaglandins because of ductus arteriosus-dependent heart disease, and $\beta$-blockers were co-administered to three children because of obstruction of the left ventricular outflow track.

All children had transthoracic echocardiography prior to $\mathrm{CPB}$; left ventricular ejection fraction was evaluated at $60 \%$ (25 to 78 ) with normal values ( $>50 \%$ ) observed in 34 patients $(87 \%)$. Ventricular diastolic function was not assessed. Eleven children were cyanotic $(\mathrm{SpO} 2<90 \%)$ prior to the surgery because of their congenital heart disease. Open heart surgeries were as follows: arterial switch $(n=9)$, repair of complete atrioventricular canal $(n=6)$, repair of ventricular septal defect $(n=6)$, total repair of tetralogy of Fallot $(n=4)$, pulmonary valvuloplasty $(n=3)$, repair of coarctation and ventricular septal defect closure $(n=2)$, repair of interrupted aortic arch with ventricular septal defect closure $(n=2)$, repair of double-outlet right ventricle $(n=2)$, repair of pulmonary artery stenosis $(n=2)$, pulmonary valvular replacement $(\mathrm{n}=2)$, and repair of truncus arteriosus $(n=1)$. Surgery with deep hypothermic circulatory arrest was necessary in 11 children.

In the operating room all children required the following: a red blood cell transfusion, fresh-frozen plasma administration, neuromuscular blocking agents, and hypnotic and opioid drug infusion. Ultrafiltration of $650 \mathrm{~mL}(250$ to 1,200$)$ of fluid during CPB was performed to achieve a negative fluid balance and hematocrit at $44 \%$ (35 to 47). Milrinone and Ep were initiated just before weaning from $\mathrm{CPB}$, with an infused Ep dose of $0.07 \mu \mathrm{g} \cdot \mathrm{kg}^{-1} \cdot \mathrm{min}^{-1}(0.01$ to 0.23$)$ and an infusion milrinone dose of $0.5 \mu \mathrm{g} \cdot \mathrm{kg}^{-1} \cdot \mathrm{min}^{-1}$ (0.2 to 0.7$)$. Milrinone infusion was stopped after 1.5 days (1 to 13 ).

Delayed sternal closure occurred in four patients. Postoperative left ventricular ejection fraction under Ep and milrinone infusion was at $60 \%$ (30 to 70) with normal values $(>50 \%)$ observed in 34 patients $(87 \%)$. CVP and LAP were $11 \mathrm{mmHg}$ ( 8 to 15 ) and $8 \mathrm{mmHg}$ (6 to 14), respectively. Four children exhibited supraventricular tachycardia, one had ventricular tachycardia and five had a transient atrioventricular block, which required external cardiac pacing. Urine output was $4.5 \mathrm{~mL} \cdot \mathrm{kg} \cdot \mathrm{h}^{-1}(0.8$ to 7.5$)$ and $\mathrm{pH}$, plasma $\mathrm{HCO}_{3}^{-}\left(\mathrm{mmol} \cdot \mathrm{L}^{-1}\right)$ and plasma ionized calcium $\left(\mathrm{mmol} \cdot \mathrm{L}^{-1}\right)$ levels were: 7.39 (7.27 to 7.45); 24 (20 to 26 ) and 1.28 (1.12 to 1.5 ), respectively. All children required diuretics, whereas none were under corticosteroid therapy during the 6 hours following surgery. Ten children needed inhaled nitric oxide for pulmonary arterial hypertension during the postoperative course. Endotracheal mechanical ventilation was performed for all patients during 2.1 days ( 1 to 17 ). None of the patients required renal replacement therapy and none had liver injury according to prothrombin activity and/or Factor V levels (lower than $50 \%$ for at least 24 hours). None of the children died during their pCVICU stay. Finally, nine children (23\%) had LCOS according to the classical definition. Table 1 summarizes overall patient characteristics.

\section{Epinephrine pharmacokinetics}

The increase in Ep concentration during infusion was significant: $2.94 \mu \mathrm{g} \cdot \mathrm{L}^{-1}(0.37$ to 71$)$ compared to baseline Ep concentration, $0.062 \mu \mathrm{g} \cdot \mathrm{L}^{-1}(0.037$ to 0.25$)(P<0.001)$. A one-compartment open model with linear elimination adequately described the Ep time courses. An additional movie file shows this in more detail (see Additional file 1). The pharmacokinetic parameters were V, CL and q0. The residual variability was ascribed to a proportional model. BW was the main covariate influencing $\mathrm{CL}$ and q0 $(P<0.001)$. Both PWR estimates for q0 and CL were close to 1 (0.98 and 0.985), however CL and q0 were poorly estimated (relative standard errors near 50\%). Moreover, BIC decreased from 214.2 to 205.0 when PWR was estimated and further decreased to 199.0 when PWR was fixed to $3 / 4$. Also, there was no visible or significant difference between the two models on the observed versus predicted plots. An additional movie file shows this in more detail (see Additional files 2 and 3). 
Table 1 Patient characteristics and baseline kinetic and dynamic data

\begin{tabular}{ll}
\hline Patient characteristics $(\mathbf{n}=\mathbf{3 9})$ & Values \\
\hline Demographics & \\
Age, months & $3.9(0.1$ to 189$)$ \\
Gender, male, $\mathrm{n}(\%)$ & $26(66.6 \%)$ \\
Body weight, $\mathrm{kg}$ & $4.5(2.5$ to 58$)$ \\
Preoperative physiological profile & \\
RACHS-1, categories, median (range) & 3 (2 to 4$)$ \\
Category $2, \mathrm{n}$ & 16 \\
Category $3, \mathrm{n}$ & 17 \\
Category $4, \mathrm{n}$ & 6 \\
Prothrombin activity $(\%)$ & $80(50$ to 100$)$ \\
Creatinine clearance, $\mathrm{mL} \cdot \mathrm{min}^{-1} \cdot 1.73 \mathrm{~m}^{(2)-1}$ & $91(22$ to 200)
\end{tabular}

\section{Per-operative course}

Duration of $\mathrm{CPB}$, minutes

107 (52 to 222)

Aortic cross-clamping time, minutes

64 (9 to 140$)$

\section{Postoperative course}

Ep infusion duration, days

1.5 (1 to 13$)$

pCVICU length of stay, days

3 (2 to 23 )

\section{Baseline kinetic and dynamic parameters}

Ep concentration, $\mu \mathrm{g} \cdot \mathrm{L}^{-1}$

0.062 (0.037 to 0.25$)$

Heart rate, beats. $\min ^{-1}$

135 (70 to 180 )

Mean arterial pressure, $\mathrm{mmHg}$

51 (25 to 65)

Plasma glucose level, $\mathrm{mmol} \cdot \mathrm{L}^{-1}$

6.2 (4 to 10.1 )

Plasma lactate level, $\mathrm{mmol} \cdot \mathrm{L}^{-1}$

RACHS, risk adjustment for congenital heart surgery; $n$, number; $C P B$, cardiopulmonary bypass; min, minutes; Ep, epinephrine; pCVICU, pediatric cardiovascular intensive care unit. Values represent median and the presentation of the value in parentheses defined the range from ( $\min$ to $\max$ ).

Hence, these power values were fixed to $3 / 4$ according to the BW-based allometric rule. $\mathrm{V}$ was assumed to be equal to the circulating volume because $\mathrm{V}$ could not be accurately estimated and because of the hydrophilic nature of Ep. No other covariate (gender, $\mathrm{pH}$, temperature, RACHS-1 categories, creatinine clearance, gestational age, cyanosis, malnutrition) influenced the pharmacokinetics. The final relationship for Ep CL and q0 was: then

$$
\mathrm{CL}(\mathrm{BWi})=\theta_{\mathrm{CL}} \times(\mathrm{BWi})^{3 / 4} \text { and } \mathrm{q} 0(\mathrm{BWi})=\theta_{\mathrm{q0}} \times(\mathrm{BWi})^{3 / 4} \text {, }
$$

$$
\theta_{\mathrm{CL}}\left(\mathrm{L} \cdot \mathrm{h}^{-1} \cdot \mathrm{kg}^{-1}\right)=2, \theta_{\mathrm{q} 0}\left(\mu \mathrm{g} \cdot \mathrm{h}^{-1} \cdot \mathrm{kg}^{-1}\right)=0.15
$$

where $\theta_{\mathrm{CL}}$ and $\theta_{\mathrm{q} 0}$ are typical unit clearance and endogenous production rate. For an individual weighing $10 \mathrm{~kg}$, Ep CL, q0, V and T1/2 were:

CL $(10 \mathrm{~kg})=2 \times 10^{3 / 4}=11.2 \mathrm{~L} \cdot \mathrm{h}^{-1}, \mathrm{q} 0(10 \mathrm{~kg})=0.15 \times$ $10^{3 / 4}=0.84 \mu \mathrm{g} \cdot \mathrm{h}^{-1}, \mathrm{~V}(10 \mathrm{~kg})=0.08 \times 10=0.8 \mathrm{~L}$ and $\mathrm{T}_{1 / 2}(10 \mathrm{~kg})=(\ln 2 \times \mathrm{V}(10 \mathrm{~kg}) / \mathrm{CL}(10 \mathrm{~kg})) \times 60=3$ minutes.

\begin{tabular}{|c|c|c|}
\hline Parameters & Estimate & RSE (\%) \\
\hline$\left.\overline{\theta_{\mathrm{CL}}\left(\mathrm{L} \cdot \mathrm{h}^{-1} \cdot \mathrm{kg}\right.}{ }^{-1}\right)$ & 2 & 17 \\
\hline$\theta_{\mathrm{BW}}\left(\mathrm{CL}\left(\mathrm{BW}_{\mathrm{i}}\right)=\theta_{\mathrm{CL}} \times \mathrm{BW}_{\mathrm{i}}^{3 / 4}\right)$ & 0.75 (fixed) & NA \\
\hline$\theta_{\mathrm{qo}}\left(\mu \mathrm{g} \cdot \mathrm{h}^{-1} \cdot \mathrm{kg}^{-1}\right)$ & 0.15 & 19 \\
\hline$\theta_{\mathrm{BW}}\left(\mathrm{qO}\left(\mathrm{BW}_{\mathrm{i}}\right)=\theta_{\mathrm{qO}} \times \mathrm{BW}_{\mathrm{i}}^{3 / 4}\right)$ & 0.75 (fixed) & NA \\
\hline$V(L)$ for a $10 \mathrm{Kg}$ individual & 0.8 & NA \\
\hline $\mathrm{T}_{1 / 2}(\mathrm{~min})$, for a $10 \mathrm{Kg}$ individual & 3 & NA \\
\hline$\eta_{C L}\left(\right.$ square root of $\left.\omega^{2} \mathrm{CL}\right)$ & 1 & 14 \\
\hline$\eta_{\mathrm{q} 0}$ (square root of $\omega_{\mathrm{q}}^{2}$ ) & 1.1 & 13 \\
\hline Residual variability (proportional) & 0.3 & 15 \\
\hline Correlation $\left(\eta_{C L}, \eta_{q 0}\right)$ & 0.88 & 5 \\
\hline
\end{tabular}

Table 2 Population pharmacokinetic parameters

The volume of distribution of epinephrine was ascribed to the circulating volume, estimated as a function of bodyweight (see Materials and methods). $\mathrm{CL}$, elimination clearance; $\mathrm{q} 0$, endogenous production rate; $\mathrm{V}$, volume of distribution; $C V$, circulating volume; $\theta_{\mathrm{CL}}$, typical unit clearance; $\theta_{\mathrm{q} 0}$, typical unit endogenous production rate; $\theta_{B W}$, bodyweight influential parameter; $T_{1 / 2,}$, half-life. RSE, relative standard error; $\eta$, between-subject variability (BSV); BW, bodyweight; NA, not applicable.

Table 2 summarizes the final population estimates. All parameters were estimated with good precision. Figure 1 depicts the VPC and shows that the observed concentrations were well centered around the simulated median predictions.

\section{Epinephrine hemodynamics}

After initiation of Ep infusion, (i) HR increased significantly from 135 beats $\mathrm{min}^{-1}$ (70 to 180 ) to 159 beats $\mathrm{min}^{-1}$ (80 to 212) (variance $(\mathrm{w})=2563 ; P=2.10^{-8}$ ), (ii) MAP values increased significantly from $51 \mathrm{mmHg}$ (25 to 65) to

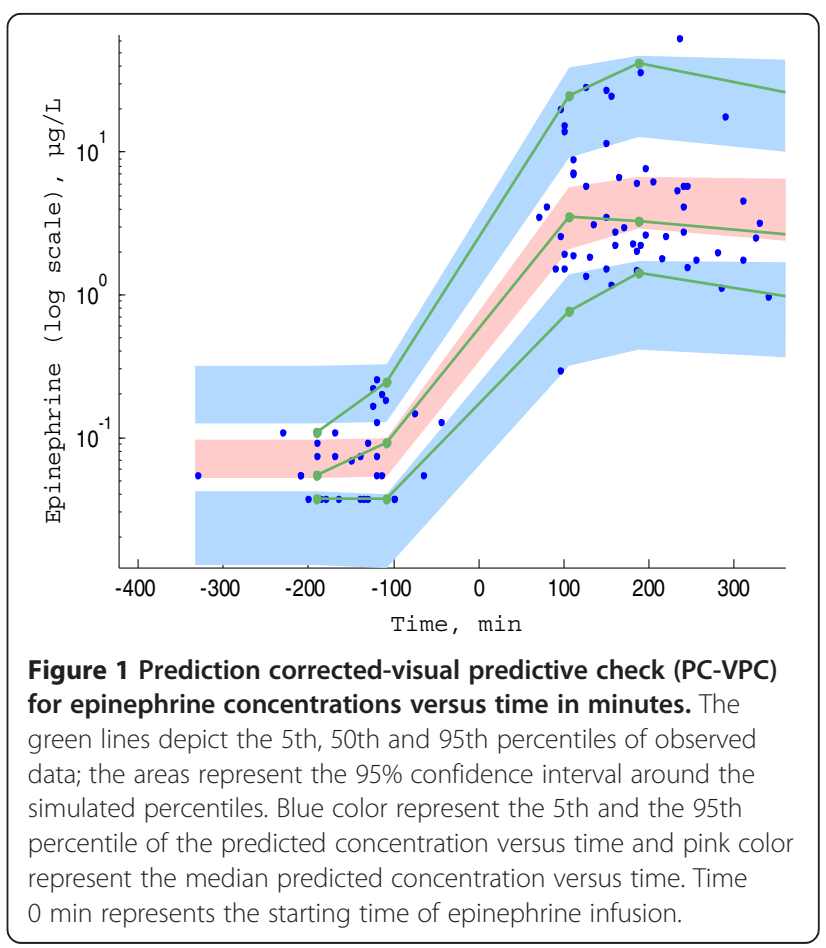


$66 \mathrm{mmHg}$ (30 to 94$)$ (variance $(\mathrm{w})=2613 ; P=5.10^{-11}$ ) (Figure 2). The variations in HR and MAP as a function of Ep concentration were well explained by the Emax models, expressed by equations (6) to (8). The residual variability was ascribed to a proportional model. BSVs were estimated for $\mathrm{HR}_{0}, \mathrm{C}_{50} \mathrm{HR}, \mathrm{SV} . \mathrm{SVR}_{0}$ and SV. $S V R_{\max }$. Age was the main covariate influencing $\mathrm{HR}_{0}$ and SV.SVR ${ }_{0}(P<0.001)$ where $\mathrm{HR}_{0 \mathrm{i}}=\mathrm{HR}_{0} \times \mathrm{age}_{\mathrm{i}}{ }^{-0.0612}$ and SV.SVR $\mathrm{Si}_{0 \mathrm{i}}=\mathrm{SV} \cdot \mathrm{SVR}_{0} \times$ age $_{\mathrm{i}}^{0.094}$ respectively. Including age in the model dramatically decreased the BIC (from 5,998 to 5,971$)$ and improved the curve-fitting of the model. In addition, RACHS- 1 category was significant $(P=0.04)$ in the estimation of SV.SVR max $: 0.44$ and 0.26 for RACHS-1 categories 2 and 3 to 4 respectively; the $B S V s$ for $H_{0}$, $\mathrm{C}_{50} \mathrm{HR}, \mathrm{SV} \cdot \mathrm{SVR}_{0}$ and SV.SVR $\max$ varied from 0.19, 1.0, 0.25 and 0.32 (basic model) to $0.14,1.22,0.13$ and 0.23 (final model). Also, the BIC decreased from 5,971 (including age) to 5,965 (final model).

No other covariate improved the model (including duration of aortic cross-clamping, duration of $\mathrm{CPB}$, deep

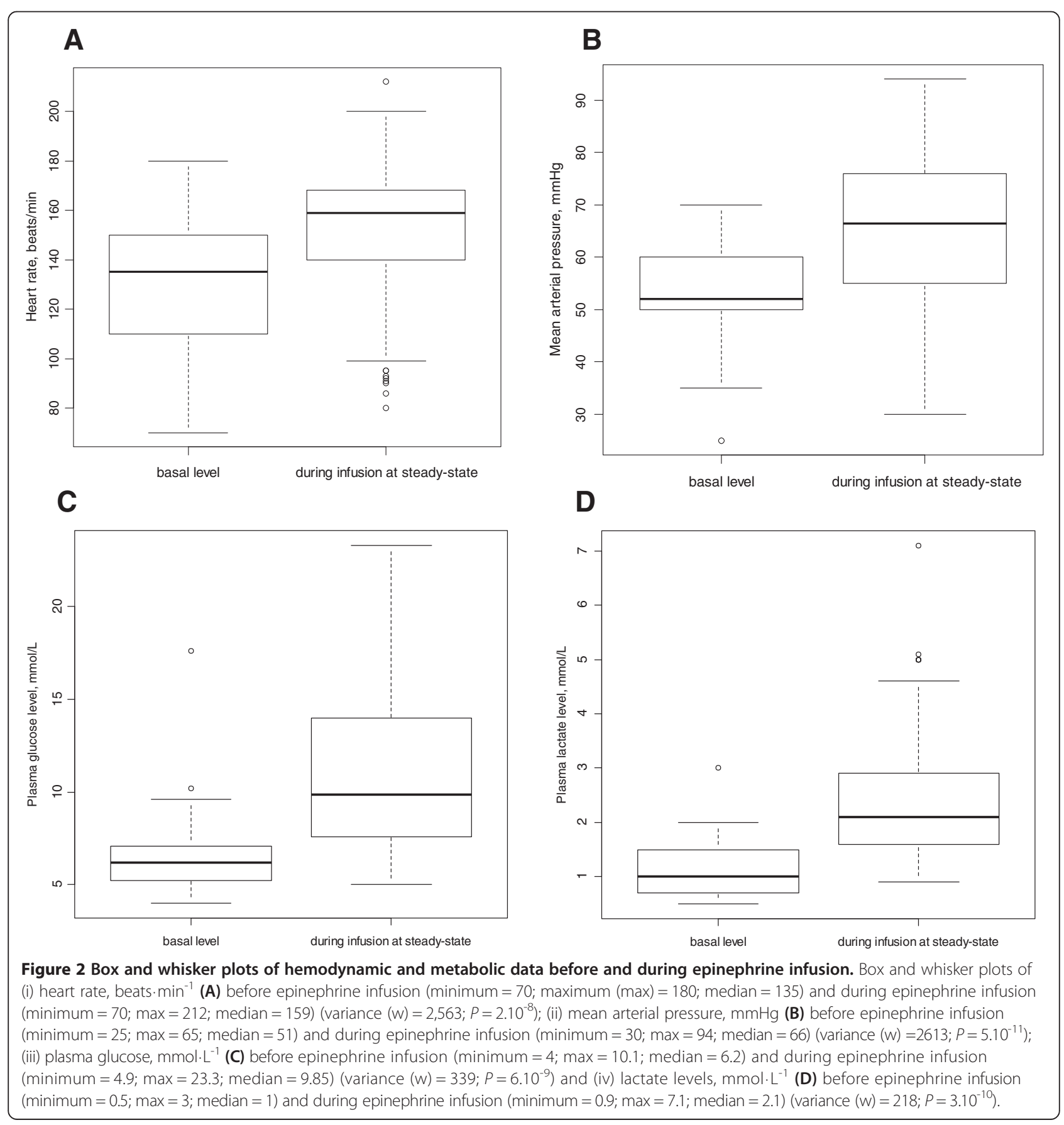


hypothermia and milrinone dosage). The final population parameters are summarized in Table 3. The VPC plots in Figure 3 show that the observed HR and MAP values are well-centered around the predicted median of the model.

\section{Metabolic effects of epinephrine}

Both plasma glucose and lactate levels increased significantly after the initiation of Ep infusion from $6.2 \mathrm{mmol} \cdot \mathrm{L}^{-1}$ (4.0 to 10.1 ) and $1 \mathrm{mmol.L} \mathrm{L}^{-1}\left(0.5\right.$ to 3 ) to $9.85 \mathrm{mmol.L} \mathrm{L}^{-1}$ (4.9

Table 3 Hemodynamic and metabolic population parameters

\begin{tabular}{|c|c|c|}
\hline Hemodynamic population parameters & Estimate & RSE (\%) \\
\hline $\mathrm{HR}_{0}\left(\mathrm{~b} \cdot \mathrm{min}^{-1}\right)$ & 133 & 3 \\
\hline$\theta_{\text {age }}\left(H R_{0 i}=H R_{0} \times\right.$ age $\left.^{-0.061}\right)$ & -0.061 & 18 \\
\hline$H R_{\max }\left(b \cdot \min ^{-1}\right)$ & 180 & 3 \\
\hline $\mathrm{C}_{50} \mathrm{HR}\left(\mu \mathrm{g} \cdot \mathrm{L}^{-1}\right)$ & 5.71 & 37 \\
\hline$S V \cdot S V R_{0}$ & 0.31 & 3 \\
\hline$\theta_{\text {age }}\left(S V \cdot S V R_{0 i}=S V \cdot S V R_{0} \times \operatorname{age}_{i}^{0.094}\right)$ & 0.094 & 14 \\
\hline SV.SVR max $_{1}$ RACHS-1 = category 2 & 0.44 & 20 \\
\hline SV.SVR $\max$, RACHS-1 = categories 3,4 & 0.26 & 20 \\
\hline $\mathrm{C}_{50} \mathrm{SV} \cdot \mathrm{SVR}\left(\mu \mathrm{g} \cdot \mathrm{L}^{-1}\right)$ & 18 & 59 \\
\hline$\eta_{H R O}$ (square root of $\omega^{2}$ HR O $)$ & 0.14 & 14 \\
\hline$\eta_{C 50 H R}$ (square root of $\omega^{2} \subset 50 \mathrm{HR}$ ) & 1.22 & 17 \\
\hline Пsv.SvRo (square root of $\omega^{2}$ sv.svRo) & 0.13 & 17 \\
\hline$\eta_{\text {sv.SVRmax }}$ (square root of $\omega^{2}$ sv.svRmax $)$ & 0.23 & 42 \\
\hline \multicolumn{3}{|l|}{ Residual variability (proportional) } \\
\hline HR & 0.08 & 4 \\
\hline MAP & 0.16 & 4 \\
\hline \multicolumn{3}{|l|}{ Metabolic population parameters } \\
\hline$G L Y_{0}\left(\mathrm{mmol} \cdot \mathrm{L}^{-1}\right)$ & 5.46 & 5 \\
\hline $\mathrm{G}_{\max }$ & 1.69 & 6 \\
\hline $\mathrm{R}_{\mathrm{GLY}}\left(\mathrm{mmol} \cdot \mathrm{L}^{-1} \cdot \mathrm{min}^{-1}\right)$ & 0.04 & 25 \\
\hline$C_{50} G L Y\left(\mu g \cdot L^{-1}\right)$ & 0.52 & 9 \\
\hline $\mathrm{LAC}_{0}\left(\mathrm{mmol} \cdot \mathrm{L}^{-1}\right)$ & 1.23 & 7 \\
\hline$\eta_{G L Y O}\left(\right.$ square root of $\omega^{2}$ GLY O) & 0.21 & 23 \\
\hline$\eta_{\text {Gmax }}$ (square root of $\omega^{2}$ Gmax $)$ & 0.213 & 26 \\
\hline$\eta_{\text {RGly }}$ (square root of $\omega^{2}$ RGLY) & 1 & 21 \\
\hline$\eta_{\text {LACO }}$ (square root of $\omega^{2}{ }_{\text {LACO }}$ ) & 0.33 & 18 \\
\hline \multicolumn{3}{|l|}{ Residual variability (constant additive) } \\
\hline $\mathrm{GLY}\left(\mathrm{mmol} \cdot \mathrm{L}^{-1}\right)$ & 2.23 & 5 \\
\hline $\mathrm{LAC}\left(\mathrm{mmol} \cdot \mathrm{L}^{-1}\right)$ & 0.5 & 11 \\
\hline
\end{tabular}

$\mathrm{HR}_{0}$, basal heart rate; $\mathrm{HR}_{\text {max }}$ maximal $\mathrm{HR} ; \mathrm{C}_{50} \mathrm{HR}$, Ep concentration producing $50 \%$ of HR maxi SV.SVR, product of stoke volume by systemic vascular resistances; SV.SVR, basal SV.SVR value; SV.SVR max $_{\text {, }}$ maximal SV.SVR value; $\mathrm{C}_{50}$ SV.SVR, Ep concentration producing $50 \%$ of SV.SVR max; RACHS-1, risk adjustment for congenital heart surgery $1 ; \mathrm{GLY}_{0}$, basal plasma glucose level; $\mathrm{R}_{\mathrm{GLY}}$, glucose zero-order production rate; $\mathrm{G}_{\max }$, relative maximal increase in $\mathrm{R}_{\mathrm{GLY}} ; \mathrm{C}_{50} \mathrm{GLY}$, Ep concentration that produces $50 \%$ of the maximal response on plasma glucose level; $\mathrm{LAC}_{0}$, basal plasma lactate level; $\mathrm{RSE}$, relative standard error; $\eta$, between-subject variability (BSV); $\theta_{\text {age, }}$ age influential parameter. to 23.3$)$ [variance $(\mathrm{w})=339 ; P=6.10^{-9}$ ] and $2.1 \mathrm{mmol} \cdot \mathrm{L}^{-1}$ (0.9 to 7.1 ) (variance $(\mathrm{w})=218 ; P=3.10^{-10}$ ), respectively (Figure 2). Assuming that Ep stimulated the glucose production rate, the turnover models expressed by equations (9) to (13) effectively described the variations in plasma glucose $(\mathrm{G}(\mathrm{t}))$ and lactate levels $(\mathrm{L}(\mathrm{t}))$. There was no significant covariate effect, including those of exogenous glucose supply, age or BW. The residual variability was ascribed to a constant additive model. BSVs were estimated for $\mathrm{GLY}_{0}$, $\mathrm{R}_{\mathrm{GLY}}, \mathrm{G}_{\max }$ and $\mathrm{LAC}_{0}$. All parameters were well-estimated with low relative standard errors. Table 3 summarizes the population estimates. The VPC plots in Figure 4 show that the observed plasma glucose and lactate levels are wellcentered around the predicted median of the model.

\section{Epinephrine dosing simulations}

Using the hemodynamic model, the effects of various infusion rates of Ep on HR and MAP were assessed as a function of age and BW. As shown in Figure 5, the increase in Ep concentration versus infusion rate was linear although the increases in HR and MAP were curvilinear, due to the Ep concentration-Emax model. Similarly, Figure 6 shows the metabolic responses for a child weighing $5 \mathrm{~kg}$ with three infusion rates: $0.02,0.1$ and $0.25 \mu \mathrm{g} \cdot \mathrm{kg} \cdot \mathrm{min}^{-1}$.

\section{Discussion}

Little is known about the pharmacokinetics and pharmacodynamics of Ep in children although this drug is used in the pediatric population. The present study using a population approach adequately described the kinetics, hemodynamic and metabolic effects of Ep in critically ill children, highlighting the between-subject variabilities which were well explained by age and BW.

\section{Epinephrine pharmacokinetics}

A one-compartment open model with linear elimination adequately described the data as previously reported $[3,5,19]$. The effect of BW using the allometric scale on clearance and Ep endogenous production improved the model and partly explained the between-subject variability [13]. This was not unexpected since endogenous rates of production and clearance of Ep are dependent on enzymatic maturation, both of which are related to age and BW [20]. With regard to endogenous Ep rate production, given that the concentrations observed following the infusion were well above 10-fold the baseline concentrations (approximately 50-fold), the contribution of possible variations in endogenous production was assumed to be negligible during the infusion. We could not adequately estimate volume of distribution because Ep concentration was measured only in the steady state; however, adjusting the volume of distribution to the circulating volume is justified considering the hydrophilic nature of Ep. We did not find any effect of 

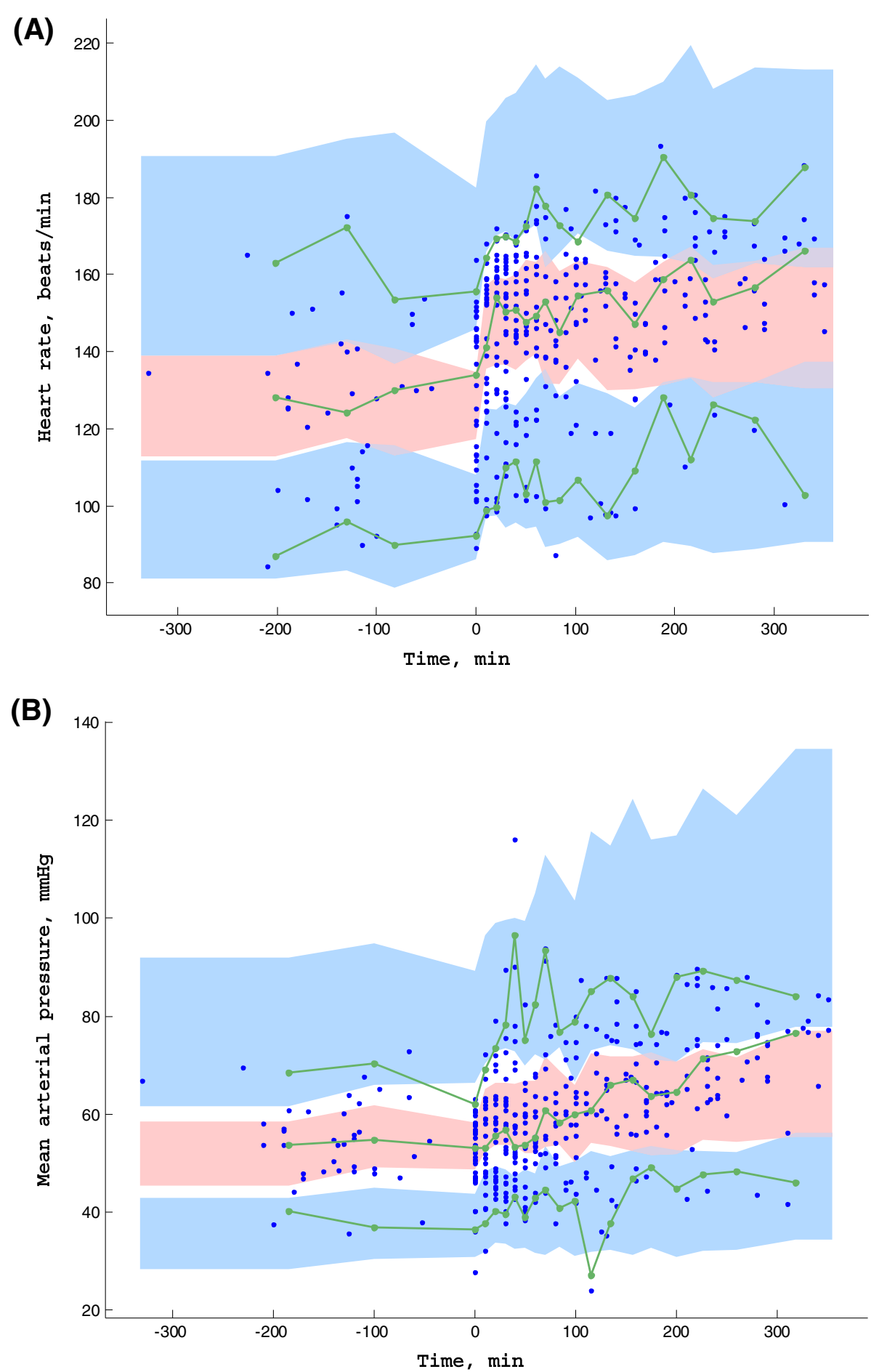

Figure 3 Prediction corrected-visual predictive check (PC-VPC) for heart rate (A) and mean arterial pressure (B) observations versus time in minutes. The green lines depict the 5th, 50th and 95th percentiles of observed data; the areas represent the $95 \%$ confidence interval around the simulated percentiles. Blue color represent the 5th and the 95th percentile of the predicted HR and MAP versus time and pink color represent the median predicted HR and MAP versus time. Time 0 min represents the starting time of epinephrine infusion.

creatinine clearance, as only $10 \%$ of Ep is excreted unchanged via the renal route and is mainly and rapidly inactivated by either methylation via the effect of
catechol-O-methyl transferase or oxidative deamination by monoamine oxidase into inactive metabolites excreted by the kidney [21]. In contrast to the study of Abboud 

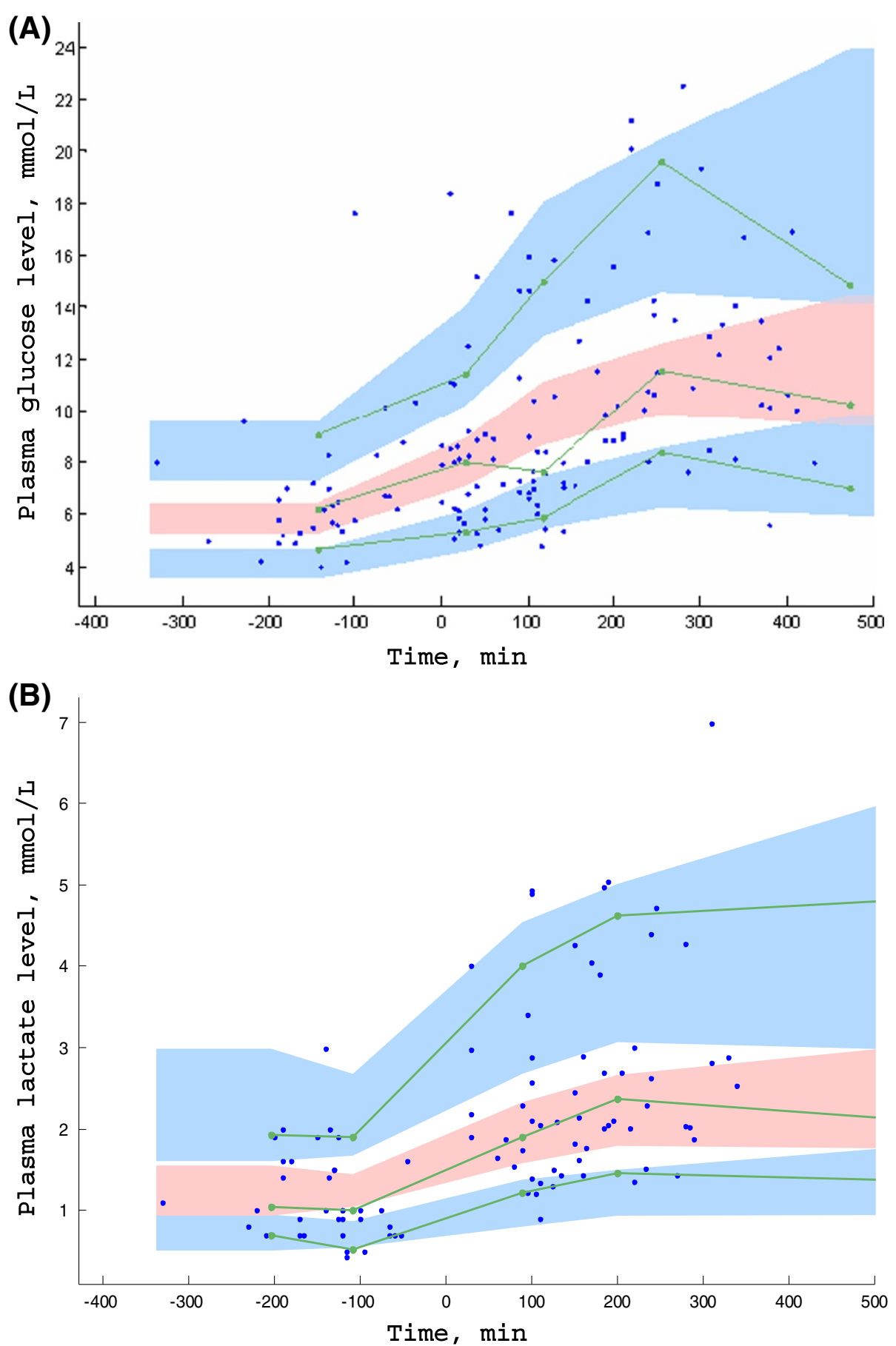

Figure 4 Prediction corrected-visual predictive check (PC-VPC) for plasma glucose level (A) and plasma lactate level (B) observations versus time in minutes. The green lines depict the 5th, 50th and 95th percentiles of observed data; the areas represent the $95 \%$ confidence interval around the simulated percentiles. Blue color represent the 5 th and the 95 th percentile of the predicted plasma glucose level and lactate level versus time and pink color represent the median predicted plasma glucose level and lactate level versus time. Time 0 min represents the starting time of epinephrine infusion.

et al., neither RACHS-1 categories nor duration of CBP or aortic cross-clamping, which reflect the severity of illness, were found to be significant, possibly because of the small sample size and the difference in patient age and illness groups between the studies [6].

\section{Epinephrine - hemodynamic effects}

To the best of our knowledge, this is the first study in which the hemodynamic responses to Ep in preventing LCOS were modeled. Only HR and MAP were recorded in this study. In adult volunteers, as in critically ill 

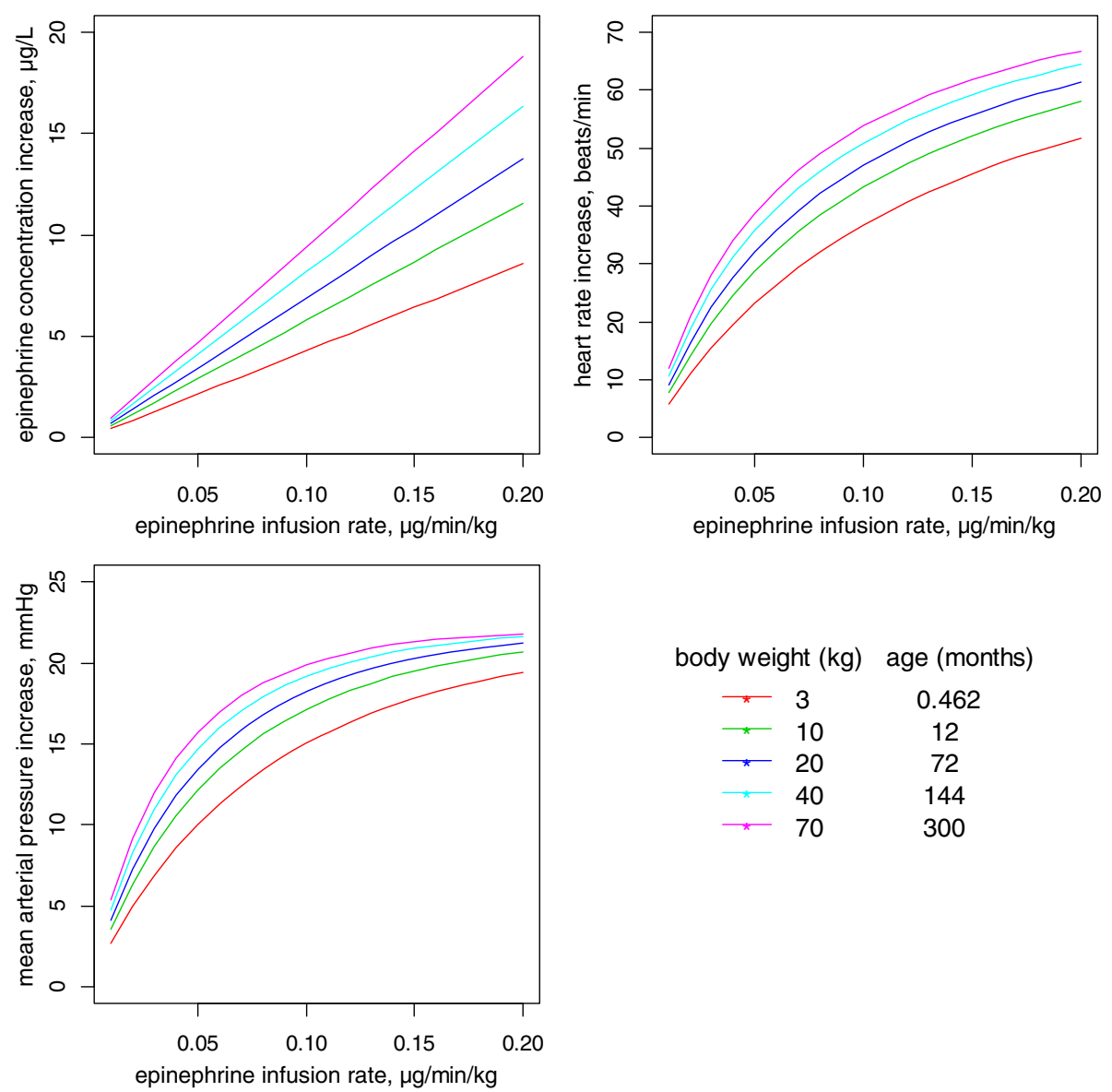

5 Dosing simulations depicting the increases in epinephrine concentration and hemodynamic responses as a function of administered infusion rate in children of different bodyweights and ages for patients with a risk adjustment for congenital heart surgery (RACHS)- 1 category of 2 .

patients, Ep increases HR as well as MAP [8,22,23]. The predominant effect of Ep when administered at low dose is mediated by $\beta$-adrenergic receptors, which increase HR and SV [23-25]. The resulting hemodynamic response may differ in children because of (i) the relative immaturity of the myocardium, which precludes a significant increase in SV [26] and (ii) a variation in $\beta 1$ and $\beta 2$-adrenergic receptor density related to age [27]. Furthermore, newborn and infant cardiac outputs are more dependent on an increase in HR [25]. This is confirmed by our hemodynamic model, which highlighted the primary role of HR, which in turn influences MAP, that is, the $C_{50}$ estimate for the SV.SVR product was three times as high as that estimated for HR, reflecting a much greater sensibility of the HR response to Ep.

The Emax models were effective in relating both HR and MAP responses to Ep concentration [28]. Measuring cardiac output is hazardous in children undergoing repair of congenital heart disease because of residual ventricular and/or auricular shunt. Hence, we could only estimate the SV.SVR product that relates MAP to HR.
Moreover, as expected, age was found to be a significant covariate that dramatically improved the model: HR was negatively related to age whereas the SV.SVR product increased with age. This latter finding is easy to explain because both SV and MAP increase with age [29]. Likewise, RACHS-1 categories 3 and 4 decreased the maximal MAP response (SV.SVR $\max$ product). This effect may be related to the role of systemic inflammatory syndrome following $\mathrm{CB}$, which alters myocardial and vascular response to Ep [11]. The impact of temperature and $\mathrm{pH}$ on HR was also investigated but was not found significant.

As milrinone was infused in all children, this could have had a confounding effect on hemodynamic responses. There are conflicting data in the literature on the effect of milrinone on HR, namely an increased or unchanged HR [30]. In the present study, none of the parameters of the hemodynamic model were found to be influenced by a dose-dependent effect of milrinone. Moreover, any possible confounding effect would be negligible since an immediate increase in HR was observed 

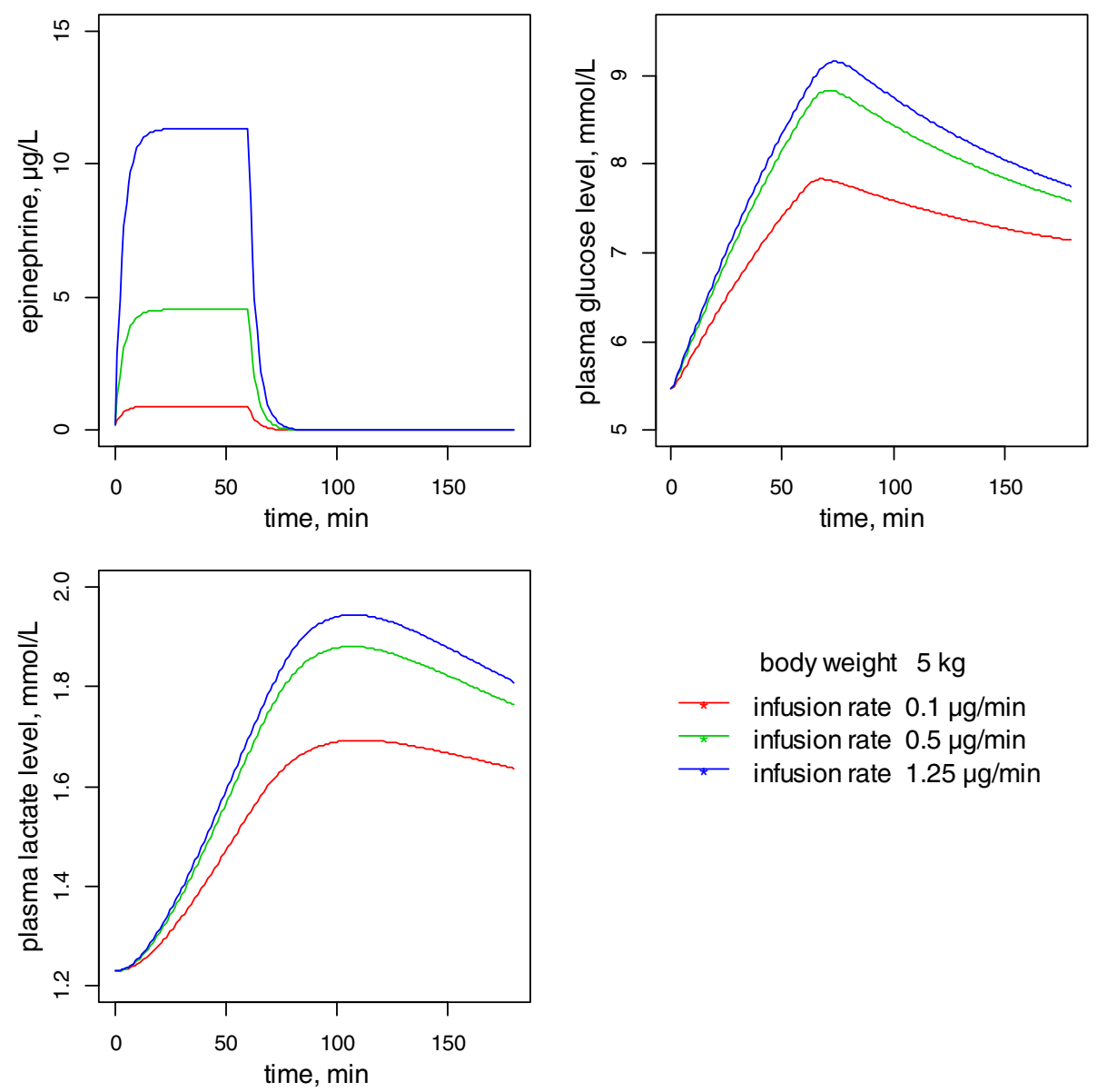

Figure 6 Time-course simulations of epinephrine concentration, plasma glucose and lactate levels following 0.02 to $0.25 \mu \mathrm{g} \cdot \mathrm{min}^{-1} \cdot \mathrm{kg}^{-1}$ epinephrine infusions in a child weighing $5 \mathrm{~kg}$.

after Ep initiation which is not compatible with the delayed response to milrinone [31].

\section{Epinephrine - metabolic effects}

The turnover model herein provided a valid relationship between Ep concentration and plasma glucose and lactate levels, as these metabolic responses are dependent on stimulation of glycogenolysis via the activation of $\beta_{2}$-adrenergic receptors [32]. During Ep infusion, the increases in plasma glucose and lactate levels were significant, albeit delayed as compared to the hemodynamic responses. Indeed, exogenous $\mathrm{Ep}$ has previously been shown to increase plasma glucose and lactate levels $[8,33]$. Lactate is mainly produced via the anaerobic glycolytic breakdown of glucose to pyruvate [32]. An excessive vasoconstriction mediated by $\alpha$-adrenergic receptors results in lactate accumulation due to limited oxygen supply [34]. However, lactate may also accumulate during accelerated aerobic glycolysis driven by Ep [35], and it is unlikely that the rise in plasma lactate level is due to an excessive vasoconstrictor effect via Ep $\alpha$-adrenergic receptor stimulation, given the low doses administered. Lastly, we believe that these increases are strongly related to Ep without confounding factors because (i) there was no significant effect of the exogenous supply of glucose, (ii) there were no other potential hyperglycemic treatments, such as corticosteroids and (iii) milrinone does not elevate glucose and/ or lactate levels [36].

\section{Epinephrine dosing simulations}

Using the final model, it was possible to highlight the differences in responses to a same infusion rate according to age or BW. Therefore, these simulations allow the determination of an a priori dosing schedule, for specific BW and age, to produce a suitable increase in HR and MAP. Interestingly, these plots clearly show that the amplitude of HR or MAP increase following various Ep infusion rates is related to the child's BW, that is, the lower the BW, the smaller the amplitude of increase. 


\section{Limitations of the study}

The small sample size likely limited the identification of other significant covariates that could affect either the pharmacokinetics or the responses to Ep. We were not able to evidence a hemodynamic effect of milrinone in the model; however, we cannot ignore the potential effect of the latter and must assume that the modeling of the hemodynamic effects of Ep, including its simulations, implicitly take into account the effects of milrinone. Furthermore, such simulations need to be confirmed in a future clinical study. Finally, as only children who underwent an open heart surgery with CPB were included, our results cannot be easily extended to patients with other circulatory failure etiologies.

\section{Conclusion}

This original study on pharmacokinetics, hemodynamic and metabolic effects of Ep to prevent postoperative LCOS in children highlights as expected, clear betweensubject variability related to the substantial role of age and BW. Taking into account these individual characteristics should help clinicians in determining an appropriate a priori dosing regimen.

\section{Key messages}

- In critically ill cardiac postoperative children, lower bodyweight was associated with lower epinephrine clearance.

- Differences of hemodynamic responses to epinephrine were related to age and bodyweight: the lower the bodyweight, the smaller the amplitude of heart rate and mean arterial pressure increase.

- Increase of plasma glucose and lactate levels was related to epinephrine concentration without any effect of age, bodyweight or exogenous glucose supply.

- Epinephrine dosing simulations should help the clinician in determining an appropriate a priori dosing regimen.

\section{Additional files}

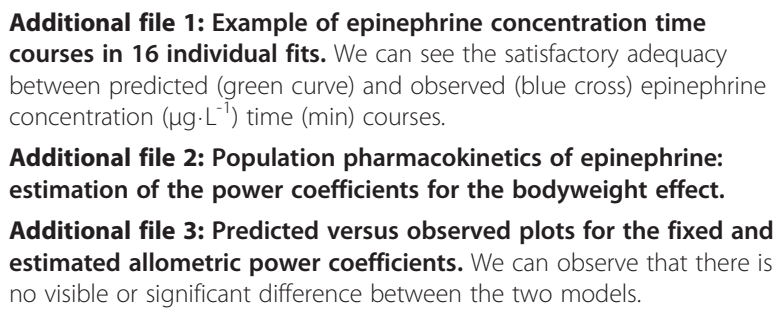

\section{Abbreviations}

A: amount; BIC: Bayesian information criterion; BSV: between-subject variability; BW: bodyweight; $C$ : concentration; $C_{50} G L Y$ : epinephrine concentration that produces $50 \%$ of the maximal response on plasma glucose level; $\mathrm{C}_{50} \mathrm{HR}$ : epinephrine concentration that induces $50 \%$ of the maximal effect on heart rate; $C_{50}$ SV.SVR: epinephrine concentration that induces $50 \%$ of the maximal effect on stroke volume-systemic vascular resistance; Circ: circulating volume; $C L$ : clearance; CPB: cardiopulmonary bypass; CVC: central venous catheter; CVP: central venous pressure; Ep: epinephrine; GLY: plasma glucose level; $G_{\max }$ : maximal increase on glucose zero-order rate production; HPLC: high-performance liquid chromatography; HR: heart rate; $\mathrm{HR}_{0}$ : basal heart rate; $H R_{\text {max }}$ : maximal heart rate value; $k_{G L Y}$ : first-order elimination rates; $k_{L A C}$ : plasma lactate elimination rate; LAC: plasma lactate level; LCOS: Iow cardiac output syndrome; MAP: mean arterial pressure; PCVICU: pediatric cardiovascular intensive care unit; PC-VPC: prediction corrected-visual predict check; PWR: power exponent; q0: endogenous production rate of epinephrine; RACHS-1: risk adjustment for congenital heart surgery 1; $R_{\mathrm{GL} \text {. }}$ : plasma glucose zero-order rate production; SD: standard deviation; SV: stroke volume; SV.SVRo: basal value of stroke volume-systemic vascular resistance product; SV.SVR $\max$ : maximal value of stroke volume-systemic vascular resistance product; SVR: systemic vascular resistance; t: time; $T_{1 / 2}$ : half-life; $V$ : volume of distribution; $\theta_{\mathrm{CL}}$ : typical unit clearance; $\theta_{\mathrm{qo}}$ : typical unit endogenous production rate.

\section{Competing interests}

The authors declare that they have no competing interests.

\section{Authors' contributions}

$\mathrm{MO}$ collected and analyzed the data, and drafted the manuscript. SU analyzed the data and drafted the manuscript. OSV made substantial contributions to the analysis and interpretation of the data. $A B$ and ID collected the data and were involved in revising the manuscript and PP was involved in critically revising the manuscript for important intellectual content. JMT conceived the study, participated in its design and coordinated and drafted the manuscript. All authors read and approved the final manuscript.

\section{Acknowledgements}

The authors thank Marie Godard, Saphia Faked, Sandra Colas, Mame Diagne, Agnes Mougenet, Isabelle Drouet, Brigitte Hubert, Claire Martinon, Marie Ange Silicani, Vanessa Lopez, Simone Gioani, and Laeticia Vaccaroni for their help in collecting data.

The funding sources were the Programme Hospitalier de Recherche Clinique régional (PHRC) AOR 11 162, 2011, "pharmacocinétique et pharmacodynamie de population des catécholamines chez l'enfant et le nouveau-né ».

\section{Author details}

${ }^{1}$ Réanimation Pédiatrique. Hôpital Necker Enfants-Malades, Assistance Publique-Hôpitaux de Paris, Université Paris Descartes, Paris, France. ${ }^{2} \mathrm{ClC}-0109$ Cochin-Necker Inserm, Unité de Recherche Clinique, Paris Centre Descartes Necker Cochin, Service de Pharmacologie Hôpital Cochin, Assistance Publique- Hôpitaux de Paris et E.A. 3620, Université Paris Descartes, Paris, France. ${ }^{3}$ Pharmacologie, Centre Hospitalier de Versailles, Université de Versailles Saint- Quentin-en-Yvelines, Le Chesnay, France. ${ }^{4}$ Réanimation Chirurgicale Cardiaque Pédiatrique. Hôpital Necker Enfants-Malades, Assistance Publique- Hôpitaux de Paris, Université Paris Descartes, Paris, France.

Received: 12 May 2013 Accepted: 9 January 2014

Published: 24 January 2014

\section{References}

1. Masse $L$, Antonacci M: Low cardiac output syndrome: identification and management. Crit Care Nurs Clin North Am 2005, 17:375-383.

2. Hoffman TM, Wernovsky G, Atz AM, Kulik TJ, Nelson DP, Chang AC, Bailey JM, Akbary A, Kocsis JF, Kaczmarek R, Spray TL, Wessel DL: Efficacy and safety of milrinone in preventing low cardiac output syndrome in infants and children after corrective surgery for congenital heart disease. Circulation 2003, 107:996-1002.

3. Vogt W, Läer S: Prevention for pediatric low cardiac output syndrome results from the European survey EuLoCOS-Paed. Paediatr Anaesth 2011, 21:1176-1184.

4. Members of the Cardiology Group, Roth SJ, Adatia I, Pearson GD: Summary proceedings from the cardiology group on postoperative cardiac dysfunction. Pediatrics 2006, 117:S40-S46. 
5. Fisher DG, Schwartz PH, Davis AL: Pharmacokinetics of exogenous epinephrine in critically ill children. Crit Care Med 1993, 21:111-117.

6. Abboud I, Lerolle N, Urien S, Tadié JM, Leviel F, Fagon JY, Faisy C: Pharmacokinetics of epinephrine in patients with septic shock: modelization and interaction with endogenous neurohormonal status. Crit Care 2009, 13:R120.

7. Booker PD: Pharmacological support for children with myocardial dysfunction. Paediatr Anaesth 2002, 12:5-25.

8. Valverde E, Pellicer A, Madero R, Elorza D, Quero J, Cabañas F: Dopamine versus epinephrine for cardiovascular support in low birth weight infants: analysis of systemic effects and neonatal clinical outcomes. Pediatrics 2006, 117:e1213-e1222.

9. Allegaert K, Langhendries JP, van den Anker JN: Educational paper: Do we need neonatal clinical pharmacologists? Eur J Pediatr 2013, 172:429-435.

10. Jenkins KJ, Gauvreau K, Newburger JW, Spray TL, Moller JH, lezzoni LI: Consensus-based method for risk adjustment for surgery for congenital heart disease. J Thorac Cardiovasc Surg 2002, 123:110-118.

11. Bronicki RA, Chang AC: Management of the postoperative pediatric cardiac surgical patient. Crit Care Med 2011, 39:1974-1984.

12. Guillemin A, Troupel S, Galli A: Determination of catecholamines in plasma by high-performance liquid chromatography. Clin Chem 1988, 34:1913-1914.

13. Anderson BJ, Holford NH: Mechanism-based concepts of size and maturity in pharmacokinetics. Annu Rev Pharmacol Toxicol 2008, 48:303-332.

14. Riley AA, Arakawa Y, Worley S, Duncan BW, Fukamachi K: Circulating blood volumes: a review of measurement techniques and a meta-analysis in children. ASAIO J 2010, 56:260-264.

15. Milnor WR: Hemodynamics. Baltimore: Williams \& Wilkins; 1982:157-271.

16. Lixoft. [http://www.lixoft.com/]

17. Kuhn E, Lavielle M: Maximum likelihood estimation in nonlinear mixed effects models. Comput Stat Data Analysis 2005, 49:1020-1030.

18. Bergstrand M, Hooker AC, Wallin JE, Karlsson MO: Prediction-corrected visual predictive checks for diagnosing nonlinear mixed-effects models. AAPS J 2011, 13:143-151.

19. Clutter WE, Bier DM, Shah SD, Cryer PE: Epinephrine plasma metabolic clearance rates and physiologic thresholds for metabolic and hemodynamic actions in man. Clin Invest 1980, 66:94-101.

20. Steinberg C, Notterman DA: Pharmacokinetics of cardiovascular drugs in children. Inotropes and vasopressors. Clin Pharmacokinet 1994, 27:345-367.

21. Kopin IJ: Catecholamine metabolism: basic aspects and clinical significance. Pharmacol Rev 1985, 37:333-364.

22. Gillies M, Bellomo R, Doolan L, Buxton B: Bench-to-bedside review: Inotropic drug therapy after adult cardiac surgery - a systematic literature review. Crit Care 2005, 9:266-279.

23. Moran JL, O'Fathartaigh MS, Peisach AR, Chapman MJ, Leppard P: Epinephrine as an inotropic agent in septic shock: a dose profile analysis. Crit Care Med 1993, 21:70-77.

24. Chernow B, Rainey TG, Lake CR: Endogenous and exogenous catecholamines in critical care medicine. Crit Care Med 1982, 10:409-416

25. Pellicer A, Valverde E, Elorza MD, Madero R, Gayá F, Quero J: Cabañas: Cardiovascular support for low birth weight infants and cerebral hemodynamics: a randomized, blinded, clinical trial. Pediatrics 2005 115:1501-1512.

26. Perloff WH: Physiology of the heart and circulation. In Cardiovascular Problems in Pediatric Critical Care. Edited by Swedlow DB, Raphaely RC. New York: Churchill Livingstone; 1986:1-86.

27. Kozlik R, Kramer HH, Wicht H, Krian A, Ostermeyer J, Reinhardt D: Myocardial beta adrenoceptor density and the distribution of beta1 and beta2 subpopulations in children with congenital heart disease. Eur J Pediatr 1991, 150:388-394.

28. Dewachter P, Jouan-Hureaux V, Lartaud I, Bello G, de Talancé N, Longrois D, Mertes PM: Comparison of arginine vasopressin, terlipressin, or epinephrine to correct hypotension in a model of anaphylactic shock in anesthetized brown Norway rats. Anesthesiology 2006, 104:734-741.

29. Cattermole GN, Leung PY, Mak PS, Chan SS, Graham CA, Rainer TH: The normal ranges of cardiovascular parameters in children measured using the ultrasonic cardiac output monitor. Crit Care Med 2010, 38:1875-1881.

30. Duggal B, Pratap U, Slavik Z, Kaplanova J, Macrae D: Milrinone and low cardiac output following cardiac surgery in infants: is there a direct myocardial effect? Pediatr Cardiol 2005, 26:642-645.
31. Bailey JM, Miller BE, Lu W, Tosone SR, Kanter KR, Tam VK: The pharmacokinetics of milrinone in pediatric patients after cardiac surgery. Anesthesiology 1999, 90:1012-1018.

32. Bearn AG, Billing B, Sherlock S: The effect of adrenaline and noradrenaline on hepatic blood flow and splanchnic carbohydrate metabolism in man. J Physiol 1951, 115:430-441.

33. Levy B: Bench-to-bedside review: Is there a place for epinephrine in septic shock? Crit Care 2005, 9:561-565.

34. Duke T: Dysoxia and lactate. Arch Dis Child 1999, 81:343-350.

35. Levy B: Lactate and shock: the metabolic view. Curr Opin Crit Care 2006, 12:315-321.

36. Heringlake $M$, Wernerus M, Grünefeld J, Klaus S, Heinze $H$, Bechtel M, Bahlmann L, Poeling J, Schön J: The metabolic and renal effects of adrenaline and milrinone in patients with myocardial dysfunction after coronary artery bypass grafting. Crit Care 2007, 11:R51.

doi:10.1186/cc13707

Cite this article as: Oualha et al:: Pharmacokinetics, hemodynamic and metabolic effects of epinephrine to prevent post-operative low cardiac output syndrome in children. Critical Care 2014 18:R23.

\section{Submit your next manuscript to BioMed Central and take full advantage of:}

- Convenient online submission

- Thorough peer review

- No space constraints or color figure charges

- Immediate publication on acceptance

- Inclusion in PubMed, CAS, Scopus and Google Scholar

- Research which is freely available for redistribution 